\title{
Being old in the consumption society: body, media and social representation
}

\begin{abstract}
With scientific advancement allied to medicine, the elderly population has been growing exponentially across the world. In Brazil, the average life expectancy rises as well, though without a positive image of the elderly in work and social environments that they frequent. Working with the premise that the social phenomena of ageism happens because of the fact that in modern society, youth has become an utmost value as opposed to a natural stage in the cycle of life, this article aims to analyze social representations of the elderly. For such end, Brazilian media images, as well as the moral judgment made upon them in the Brazilian social imaginary, will be analyzed.
\end{abstract}

Keywords: elderly, social representation, media, consumption society
Volume 3 Issue 2 - 2018

\author{
Joana De Vilhena Novaes, Anderson Barreto, \\ Bruna Madureira, Junia De Vilhena \\ Department of Psychology, Universidade Veiga de Almeida \\ (UVA)/Pontificia Universidade Católica do Rio de Janeiro (PUC- \\ Rio), Brazil
}

\begin{abstract}
Correspondence: Joana De Vilhena Novaes, Department of Psychology, Universidade Veiga de Almeida (UVA)/Pontificia Universidade Católica do Rio de Janeiro (PUC-Rio), Brazil, Email joanavnovaes@gmail.com
\end{abstract}

Received: March 23, 2018 | Published: April II, 2018

\section{Introduction}

Medical advances, scientific and technologic research, sanitation and care for dieting and a wider care for health were determinant factors for the aging of populations. The world wide longevity is a reality that brings positive and negative social impact. The increase in life expectancy brings taxing consequences to other sector such as pensions and health care systems. WHO estimations stipulate that by 2020 the world will have more of the elderly than children younger than five. It should be noted that this projection does not show signs of decline.

However, longevity should not be seen exclusively as "living longer." It's necessary, above all, to age with quality of life. The many years added to life must be thought of socially as another factor, the life added to new years. That is when the concept of quality of life becomes synonymous with successful aging. ${ }^{1}$ Aging when allied to quality of life would not be synonymous with not being ill but connected to a wider concept that comes from a biopsychosocial process. However, this process is often represented, most of the time, by losses. In what concerns the biological side, it would show through the weakening of the muscles, the decline of bodily and cognitive functions. In what concerns the psychological aspect, however, it's also taken into consideration the psychic life of the individual, with the subjective gains and losses from the transformations imposed by the environment; and the social, through the roles played in the everyday relations with themselves and others. ${ }^{1}$

The way that a society sees their population aging process is measured by cultural and traditional values. The infra and extra family relations are important types of sociability, as well as seeing longevity in a positive manner, as opposed to a negative sentence.

The collective imaginary around aging is strongly attached to the feeling of loss, and, in the current scenario, loss is unavoidably connected to death and endings, which might be lived through retirement and the ceasing of workplace production. All of this are factors that might cause psychic imbalance in the individual. Bauman ${ }^{2}$ says that although death has not been abolished, the strong medical culture that the contemporary subject is inserted in makes the theme temporarily vanish from discourse. The price to be paid is a life that's been policed from beginning to end.

In "The loneliness of dying", Elias, ${ }^{3}$ says that life is a problem for the living, and since culturally we do not see death in good terms, it is put aside, making it hard to face it, specially during the aging process. In "Thoughts for the Times on War and Death" Freud, ${ }^{4}$ has the following analysis: "[...] supporting life is still the first duty of the living. [...] If you wish to endure life, prepare yourself for death". The social representation of old age, as intrinsically connected to death, is not only a matter for the elderly, since after all death comes at any moment.

Being born, growing up and dying don't seem to be beginnings of reaching old age. It's subjective relations, however, that many times make men hopeful with its own immortality, allied and strengthened by the belief that medicine will delay the end to human life for a long time.

Aging presents itself as a social diagnosis to people who reach their $60 \mathrm{~s}$. The symbolic representation of old age and subjective relations seem to lead to social and emotional isolation. In families there is a clear divide between grandparents and their grandchildren, as well as elderly parents and their children. We live in a time where aging parents find orphans in their living children. The divide between those who don't wish to be a burden, in one side, and those who do not wish to be burdened in another is a new family setting. Abandoned, therefore, elderly people lose all status they built through life. If human beings are social beings it is in old age that, sadly, it can be noted how affection or affective or sympathetic relationships become something difficult, as though the elderly didn't have the right to live life with affection or tenderness.

As it is known, chronologic time is not the same as social, biologic or existential time. There is a demand of modern days that old people don't age, as to match all expectations around us, like the one of taking care of appearances (working out, wearing anti-aging makeup, surgery and etc). However, the elderly need leisure time and 
to remember their lives' dear moments. To this process it is added the natural losses of old age, bringing about a social exclusion that unavoidably generates loneliness and isolation. The elderly become a social problem, as they are not productive and create social spending, taxing pensions immensely - their knowledge no longer is seen as the currency exchange of other times. It's in this present scenario that we can witness a society that, if it can't devour the elderly, finds a consumer's market that may lead to their segregation.

Cast out of social spaces, the elderly live in bitter margins of society and symbolic invisibility. Their existence, gradually, loses all meaning and tears social bonds. If, on one hand, scientific and technological advancement lead to longer life expectancy, on the other hand, it's necessary to question the quality of this new found longevity created by medicine. If people live longer, is that worth it, if this life is cause for suffering and social exclusion?It's possible to realize, equally, that man has not beaten death or has been successful in better represent its end, and with this, its representation is made distant from us - through a scientific project, allied to modern medicine, which waves the promise of eternal life. Here it's worth questioning again, what is the quality referential of that which is supposed to be eternal life.

Frequent popular expressions such as "old people stuff"; "old age" and "all old people are the same", can be seen as ways to avoid conflicts with the time for senility, once all avoidance is frequently a way to mitigate the anguish of death, as it pushes away, although temporarily, the end of consciousness. Many elderly look for the place of silence as a way to avoid put into words their psychic pain. In the same way, the shame for a devalued condition is another feeling that takes over the elderly, which begins, a lot of times, inside their own houses with their family members (including their children).

With consumption being made the center, there are, however, the other subjective aspects for the placement of the elderly in society. In this way, the clash with retirement would be one of the negative pillars of this transformation. In a culture that values high performance as a maximum value, old age is synonymous with slowness and low productivity. Therefore, old people must be replaced quickly and their knowledge and experience, left aside and devalued.

The ideal of retirement as a reward of years of labour, once represented as a time for rest and leisure - now reveals itself to be the opposite! It is a death sentence that shows, equally, production value: the elderly are scraps. In a society led by information, where knowledge can be accessed instantaneously, wide and without restrictions on the internet, the image of the elderly lose their exchange value. The image of the elderly as a source of ancestral knowledge is replaced by the one of discartable and obsolete objects and things with no use. Retiring, at last, is a kind of social disability.

Bauman $^{2}$ reminds us that pensions have stopped being a citizen's right, representing now an expensive social weight dead for capitalist society. The way to deal with this by the system seems to have been diminishing the physical and cognitive abilities of man, followed by separating their social activities. In this way, the accumulation of knowledge and experience of this stage in life seems not to find a market equivalent.

Debert $^{5}$ reinforces that capitalism is a negative way to accentuate the social representations of old age, since they are not part of the workforce, which leads to abandonment both from the State and from society. Valuing physical strength and productivity resulted in disqualifying the elderly. The social importance of the elderly has become inexpressive in the 21 th century. This can be easily understood as what is highlighted on the elder are the losses, not the emotional and professional achievements etc.

Vilhena, Novaes \& $\operatorname{Rosa}^{6}$ consider that being old in western capitalist society means being physically and intellectually incapable, which means they now occupy the space of physical and psychic decay. The glory of young men is their strength, And the splendor of old men is their gray hair (Proverbs, 20,29). The Bible quote is not represented in modern society, for there is no more glory in aging and the space for the elderly, as a central figure, has been loss and so has its value. Here there are two antagonic forces: youth and aging - being the first the main force of modern times and the other its waste.

The existence of intergenerational conflicts is one of representations of these extremes. Youth represents technology, advancement, the future while old people become associated with the obsolete and out of fashion. Youth has become a life value and no longer just a restricted part of the human life cycle. With this, the elderly are a social burden. Nothing clearer than the blame pensioners carry for the "hole" in social security and the economic problems generated for those that do not contribute.

Youth, then, became the only possible ruling model of how to be, exist, and relate in current times. This means that not meeting this standard will be considered a deviation, a transgression. Elias ${ }^{3}$ helps us better understand the place where the elderly is put today by saying that the old are not what is called "normal". Normal is being young and being old causes disgust, as nobody wishes to get old. It's postmodern truths that lead to prejudice and ageism while the horror to aging, as well as the intolerance that the popular imagination has been developing in relation to old people. Youth cannot, and does not wish to, put itself in the place of the old. Far from wanting to relate to the elderly, youth denies its value and its frame of reference and value in what wisdom and life experiences are concerned.

\section{The example and the counter-example}

Still, it's interesting to notice the way in which the severe social rules act upon the elderly. Cases such as the one that took place with the actress Betty Faria ${ }^{1}$ in the year of 2013 make us consider the harshness in the gaze and the impossibility to handle and accept the elderly body, which now causes disgust and repulse. Upon being seen and photographed in a south end Rio de Janeiro beach, the 72 years old actress was victim of jeers and criticisms on social media because of her pictures in a bikini made public online. The fact that she was wearing an outfit of ordinary use among women caused discomfort and disgust. However what this overblown and nervous reaction make us think is how only the young have the right to dress as they wish or show their bodies, and even graver still, only the young have right to move freely in public environments of great diversity in classes and cultures, such as the beach. If the elderly wish to use spaces such this, they must be modest and thoughtful, because of the rules on their bodies and behaviour.

The actress suffered hostility and the episode was published across the media. Some time later, Betty Faria returned to the same beach, now wearing a swimsuit. Once more we think about how

\footnotetext{
${ }^{1}$ After argument, Betty Faria goes to the beach in a swimsuit. http://ego.globo. com/praia/noticia/2013/07/apos-polemica-sobre-biquini-betty-faria-vai-praiade-maio.html - acessado em 14/04/2016.
} 
much the angry and offensive normative discourse leads to a rejection in exposing the elderly body, which brings in itself the scars of life and time. The choice for a "shyer" outfit seems to indicate a more conservative and ashamed posture, and within the traditional models of femininity and aging, the piece of clothing is associated with a more "matching" behavior with a woman around her 70s. In this way is worth mentioning that patriarchal marks are all over the normatization of bodies, once bodies of the same age are not targeted in the same way about the inadequacy of their bodies.

On the norms and regulations on the elderly body, Sibilia? highlights that socially the elderly body, as though it's something indecent, should not be shown. The current times use tools such as filters and retouches on image as a way to soften and reduce the rejection or anger caused to the eyes by the aging body.

Among this growing tyranny of youthful looks, old age is censored as though it was something obscene and embarrassing, that should remain hidden, out of frame, unable to desire the so important visibility (p.97).

On what concerns dressing, discussions about the kind of clothing understood as supposedly being adequate for the elderly - "old people clothes" - or how they should behave in public is a reflex of how modern subjectivity is built. "Mass media exalts the young, the body and sexuality, a historical degradation of certain structures under the sign of consumption". 8

In television, one of the most representative icons is the actress Suzana Vieira. At 75 years old, she is frequently in the covers of magazines showing her body - with retouched images, it's worth mentioning - and news involve her body. In February, 2015 in a interview for the TV show Encontro com Fatima Bernardes, the actress said "I never said I was old, because wasn't, I am." "Owning" her old age and identifying herself as something that was given and assumed of her. Her attitude deliberately seems to make the repercussions surrounding the discussion easier, like the use of big cleavages and the relationships with younger men, used by the media to "sell" the news. Again we realize that youth has become the utmost value in modern times.

In March, 2016, pictures of the actress on Instagram were again a media focus. Complimented for her body, the actress says in her instagram: Life ends at how old? While there we are alive, we are living! I am youthful. I will die this way. Some sad people at their 20s don't know how to express themselves, repress their sexuality and are too cowardly to love. Being youthful means being open to life (Vieira, 2016).

Fernandes, ${ }^{9}$ says that: "[...] currently the emphasis is in the exterior. [...] the body and image worship finds horror in aging and death, the negative that justifies the possibility of its existence" (p.81). The projection of a body in shape, based on a rigid schedule of workouts and dieting denote a constant concern in looking youthful, even if one affirms and recognizes they are old. The body shape and the frequent (re)arrangement of looks are taken to the paroxysm of current times: the body no longer is presented, but is represented and this representation takes place, mainly in virtual environments of social networks, with Instagram above all.

In aforementioned examples, two identity models are offered respectively: on one side, Suzana Vieira and the mimicry of a youthfulness achieved through the discipline of many body practices; on the other, Betty Faria as the personification of shame and embarrassment, experienced by all of those who seek to follow the norms through avoiding public spaces. Weight and old age are then intimately connected to being ugly. Alongside fatness, ${ }^{10}$ old age occupies a marginal place where it represents the ugly that one wishes to hide.

\section{The ship of the excluded}

Opposing beauty and ugliness, we associated youth with the beautiful and old age with the ugliness paradigm. In this new order of values, in which death is a taboo, history, represented by the passage of time, is no longer a value like it is in societies that anchor their norms and costumes in tradition. After all, as Mary Del Priore ${ }^{11}$ reminds us, what's the use of history in a country with no memory?

Following this thought, the non-softening of the passage of time, through the intervention against the undesirable traits of aging, is understood as a moral transgression. From the civilization process that builds the social processes responsible for the body worship in the consumption society, it is possible to understand the esthetic interventions as a hygiene practice instead of a class frivolity.

Novaes $^{12}$ says that "deviation from the aesthetic 'in fashion' sends the subject, specially women, to the limbo of exclusion and the exhaustive practices of body worship." For women, beauty is represented as a cultural duty, and therefore, a moral one, which allows us to understand the rule that ugliness is lesser valued point in the female universe: the ugly woman, therefore, is less of a woman, since beauty is a female attribute And what are, in this context, the most valued representations of youth? Youth and thinness.

In this way, the right to beauty has become a duty, as Novaes reminds us. ${ }^{13,14}$ This research verifies the modern imposition of youth and beauty to an aging population and, because of this, loses its significance. In this "spectacle society" [...] where everyone is judged by what is seen in their bodies and their purely visible actions, aging is a denied right..$^{15}$ The subject is replaced by an image construction of something ideal, here being the toned, strong and lively body.

The body as a capital, in a culture that privileges high productivity, excellent performance, speed and lightness - attributes intimately related to youth - finds in aging a problem and in the elderly, the leftovers. Another example we believe to be important in legitimizing the thought process we tried to build here is the one of actor Stênio Garcia $^{2}$ that, in 2015,83 years of age, had photos of his intimate conjugal moment leaked online.

"Nudes", a mark of the current times, like the selfie, has caused discomfort and aggressive comments toward the couple. The repercussion of the case was wide, but with less importance when compared to events in which the nudity of a woman was exposed, like for example, the intimate images of actress Carolina Dieckman made public. This episode was made into a law against crimes of breaching and publicizing data of a personal nature. We believe it's legitimate to say that the actor's video didn't cause as much impact in public opinion because, in Brazil, sex in the masculine universe indicates virility, while for women, it is still associated with promiscuity - a fact that is revealing in how archaic, retrograde and conservative the social

"'I felt like I was raped, Stenio Garcia's wife says". http://g1.globo.com/ rio-de-janeiro/noticia/2015/09/me-senti-estuprada-afirma-mulher-de-steniogarcia-sobre-fotos-vazadas.html - Acessed in 21/09/2016. 
imaginary is in Brazil.

Bobbio $^{16}$ says that the old is not beautiful and the fact above helps the statement about exalting the young body. The indignation and the cruel criticism, in the case of actresses is larger than the ones suffered by the actor.

Ortega \& Vidal ${ }^{17}$ highlight the submissive condition of the body and says the current times are represented by bio identities. The same refer to the self-control, policing and management that are inserted and assimilated efficiently by the subject itself. Within this scenario, the subject takes in the responsibility for their identity. "Strength, rigidity, youth, longevity, health, beauty are new criteria which evaluate the worth of a person and condition their actions." (p. 34).

In this way, the stigma over the elderly and the fat makes what we understand as a socially validated exclusion (Novaes, op.cit.). "In the course of aging, human beings are compelled to confront the disqualification of the elderly body which is a social mark of decay, ugliness, illness, and being closer to death". ${ }^{18}$

And for Novaes \& Rosa, ${ }^{19}$ “ "...] the body, in old age is a privileged site of narcissistic delusion, fated to decay and death and a stage for illness, pushing the subject to face the challenge to keep betting on life".

The elderly have to be active and responsible for their own health and well being. Goals such as longevity, physical prowess and youthfulness point to precedence of an independent body. In this way, as its logical for neoliberalism and its production order, aging is regulated to make retirement pensions and health become increasingly less as a government to promote justice and social inequality, and more as a dead weight to be ripped off for the advancement and development of the economy.

For Ortega \& Vidal, ${ }^{17}$ the elderly have to make themselves an autonomous individual capable to take care of themselves. In his reflections on the theme, the author makes a creative appropriation of classification made by Claude Fischler, ${ }^{20}$ to denominate how the contemporary imaginary sees fatness and as a consequence, obesity. For such, he presents a type of taxonomy for the elderly: "good" elderly and "bad" elderly, being that last one incapable to take care of themselves.

With this, the social rules on the elderly has the moral denotative of evil to those who don't take care of each other, and therefore do not have the will to alter their state of dependency and sedentary living, an antithesis of what is recommended by the do it yourself culture. Vilhena\& Rosa ${ }^{6}$ once again remind us that youth has ceased to be a life stage to an existence one. With this, the price paid by the framing that makes inclusion and social visibility possible is high time, money and character - modeled in what Courtine understands as an ostentatious puritanism..$^{21,22}$ According with Ortega \& Vidal, ${ }^{17}$ "the elderly of today are presented as healthy, jovial, participant, productive, self-confident and sexually active" (p.36).

\section{The social death of the old}

Targeted by a severe social ruling, like what we've seen so far, the body finds itself in a prison, source of anguish that marginalized the deviations of the new world order.

The disciplined body can achieve the so desired appearance; the wrinkles or flab become evidences of moral sloppiness and must be treated with the help of cosmetics, gymnastics, of vitamins, the leisure industry. The individuals aren't just monitored to exercise constant watch on the body, but also are made responsible for their own health, through the notion of self-inflicted illnesses, resulted by body abuses such as drink, smoke and lack of exercises. ${ }^{23}$

It's not an easy task to be and have an old body today, although this might sound paradoxical in an age that has amplified the right to old age in never seen before ways and neutralized almost all taboos that prevented body actions. We still live under the judgement of a strict body rule. Sibília ${ }^{15}$ points out that Despite all the advances, struggles and liberations that were achieved, in the 21 st century our bodies are still accused of being impure and cursed; we are under watch.

In media this discourse is increasingly ratified. In general old age is not reproduced through mass media in a positive manner or as a stage of life that adds to the others, such as childhood, youth and adulthood. Usually it is put as a stage in life that must be delayed as much as possible, including being denied. In $70 \mathrm{~s}$ and $80 \mathrm{~s}$, the role of the old was restricted to grandfathers and grandmothers, and one of the great representations of this is Dona Benta. Created by Monteiro Lobato, Dona Benta is a character from Brazilian literature that seems to embody all all the positive stamps associated to old age; she's chubby, desexualized, with a kind expression, compassionate, loved to tell fables, narrate stories from other times, and it's above all seen as a frame of reference for the young ones, a source of wisdom a safe haven for her grandchildren. The character, in its serenity, wise and resigned, seems to know very well the symbolic place that she occupies in the scenario she's inserted.

\section{The modern grandmother}

In its last live-action version for TV, in 2001, Sítio do Pica pau amarelo was remade and Dona Benta was made by Nicete Bruno. The stereotypical characteristics of the grandmother as a woman with grey hair and modest lace dresses were kept. Almost forty years since the first series went on the air, there is a generation of grandparents that are radically different from this standard. The social representation of grandparents seems to have changed a lot in very little time, as the first version was made only 40 years ago. Today grandmothers go to gyms, show themselves to be enthusiastic about social media, and control their dieting in a military way, trying to find a slender and shaped body - a symbol of accomplishment, success and victory - in the frantic search for social recognition and positivation of the aging process.

A character built in the opposite direction as Dona Benta, and thus caused many discussions, was Copélia, from the TV show "Toma lá, da cá" ${ }^{3}$. Played by Arlete Salles, the character was described as a woman of youthful and vain spirit. Even though the show was a comedy, the character tried to deconstruct the collective image of a grandmother. The ideas of consumption society are described in the character: the spirit is young. Besides that, there is a forbidding quality about being called a grandmother and have a life outside the norm (such as friendship with a "active" young woman and a active and tumultuous sex life). The character's description seems to point toward a denial of aging as the last stage in life. The image of the character is a contrast with the angelical and sweet representations of grandmothers, such as the crafty Dona Benta.

Care for the body, esthetic concern, the choice of a proper dress

3 "Toma lá, da cá" was a Brazilian series created by Maria Carmem Barbosa and Miguel Falabella and played by Globo Network between 2007 and 2009. 
code, the "old people clothes", have become basic requirements for today's grandmothers. ${ }^{24}$

From one extreme to the other, in the society of spectacle identifying models take the role of simulacra and fluidity in which the discussion of otherwise was framed in the categories of true or falls now has in plasticity and liquidity its best definition. In the words of Debord, In the technical plane, the image constructed and chosen by someone else has become the main connection of the individual to the world, which, before, looked for itself the place where they could go. From this then, it's evident that the image will be supported by everything, because inside of an image it is possible to juxtapose without contradiction anything else. [...] In this concrete experience of submission we can find the psychological root of the unanimous adhesion to what lies in it (1997, p. 188).

Freud ${ }^{4}$ reinforces that "[...] all of which we call happiness, more strictly, comes from the sudden satisfaction of highly repressed needs, and by their nature they are only possible as an episodic phenomena.". Happiness here must be understood as a feeling of well-being which takes over the subject, with avoidance and rejection of aging understood intrinsically by its association to death, as mentioned before. Baudrillard ${ }^{8}$ recognizes that happiness constitutes an absolute reference in consumption society, revealing itself as the authentic equivalent of salvation. "In the same way that an image isn't reduced to a stage, we cannot reduce aging to old age". ${ }^{24}$

Elias, ${ }^{3}$ however, highlights an important change in social position that aging causes. Being old has become a way to diagnose, leading to an isolation period and resignification. Bauman ${ }^{2}$ says that the conquest of a smooth and wrinkle-free world brings as an inexorable consequence the loss of the individual history of each subject.

In the dominant discourse, beauty standards associated with youth and thinness are unstoppable determinants. Jodelet ${ }^{25}$ reinforces that social representations are important in the everyday life of the subject, once we use them to interpret the world around us and in decision making as well, and equally, we give meaning in this way, organizing and valuing sociability relationships. In this point, finally, resides the criticism to media content production. Having diversity as a premise, which part of the population is indeed represented by this ideal of eternal youth and thinness?

\section{Elderly social representation}

According to the last census by the The Brazilian Institute of Geography and Statistics ( $\left(\mathrm{IBGE}^{4}\right)$, published in the National Research by Home Samples (Pnad) in 2013, Brazil has 23 million people aged 60 or older. Yet the consumers market, publicity and media in general, seem to only give their first steps to meet the demands of this growing group across the world.

In ads, for instance, this segment of the population seems to be portrayed as at times childish, at times as a caricature. Forget Dona Benta, knitting, pajamas or dominos. These are also stereotypes of old age.

The observation of social representations is, truly, made easier in many occasions. It circulates discourses, it's carried by words,

${ }^{4}$ Elderly are $13 \%$ of the population and the country has less children, PNAD says

http://g1.globo.com/economia/noticia/2014/09/idosos-ja-sao-13-dapopulacao-e-pais-tem-menos-criancas-afirma-pnad.html - acessed in: 24/04/2016. divulged in media's images and messages, crystallized in behaviours and material or spatial arrangements. ${ }^{25}$

The name itself has been changing in the last decades. When the average life expectancy of the population didn't reach seventy, the age distribution was done as follows: childhood, youth and seniority. With the increase of life expectancy, names are also changed, leading to the possibility of resignification and remapping the senses.

However, the meaning of old age as a deliberate choice is something for current times, where even a biological cycle such as aging seems to be subverted, taking on the impression of a deliberate moral choice that, therefore, becomes a subject responsibility.

The older adult became part of a group called "third age": the period that encompasses men and women over 60 that, however, do not feel old. The expression "we've been young the longest" used by some elderly people, denotes the point above. Would older adults be an euphemism to hide, once more, our anxiety in relation to our ends? According to Debert, "more than a chronological age, it is a way to treat older people that has not yet acquired a negative connotation." (2014, p. 119). ${ }^{26}$

As previously mentioned, being old in the modern world is an insult. Not for nothing, the recurring use of substitutes to describe the elderly. The other terms such as "best age" have also come up recently with the aim, it seems, to hide the pain and suffering of social invisibility. In the recent years, the market has started to use the term senior as synonym for the experience of those who actively age curiously, in healthcare, senior users are the ones who pay the most due to the risk and weight they represent.

To illustrate this case, we will present the release of the product Nutren Senior ${ }^{5}$, of the Nestle brand. In the website, the nutritional supplement is described in the following way: "NUTREN Senior was developed thinking about the needs of those who are over 50 and still have a lot to learn". The image representation of the product is of an elderly couple doing physical tasks without much difficulty. Both present themselves with vigor and physical disposition. However tolerance to old age in media images seems to come only paired up with the perspective of autonomy allied with productivity and agility. Old age as a time of rest, contemplation and leisure remains refuted. 27,28

Image manipulation reinforces even further the health aspects of the active aging discourse. Clothes, models and products are used in the right angle, images go through Photoshop, everything is considered in the tiniest details. Debert ${ }^{23}$ draws our attention to the origin of the representation of old age used in the ads. Referring the image of the elderly to activity and disposition, unavoidably the elderly is a part of intense consumption. That said, there are many strategies to make so the elderly won't feel old.

From this observation, demands are made for a new niche and segment of consumers. What do the elderly like? What do they wish consume? What can we sell? Do these questions lead, in last analysis, to wonder and map the consumption patterns for the old? Answers to these questions lead to the creation of new ways to consume for this population, and equally create a new social place for this new elderly subject: Where do they travel to? What should they eat? How

\footnotetext{
${ }^{5}$ Nutren Senior, Nestlé https://www.nestle.com.br/site/marcas/nutren_senior/
} Nutren_Senior_po/nutren_senior_po.aspx - acessado em 10/04/2016 
should they exercise? Which prophylactic methods for a healthy and active old age? We note then that consumption becomes a privileged highway to the re-introduction of the elderly to social scene.

In the same way, non-active old age, which means, that of introspection, rest or contemplation is rejected by campaign ads. This data has been proved by the research of SPC Brasil ${ }^{6}$, which points that $26 \%$ of the interviewed say they buy beauty products and esthetic treatment to look younger. Among the ones who wanted to keep a good appearance, $33 \%$ of the elderly interviewed, have started to invest more in clothings.

In the plane of techniques, the image constructed and chosen by someone else has become the individual's main connection with the world that, before, they looked at it by themselves, from each place they could go. From then on it's evident that the image is capable to juxtapose without contradiction of anything else. The image flow carries everything; another person commands by their own desire this simplified summary of the sensitive world, chooses where to go in this flow and also the pace of what should then manifest, with perpetual arbitrary surprise that does not leave any time for reflection, all of it independently from what the spectator might understand or think. ${ }^{29}$

\section{Final considerations}

With the coming of new scientific technology, allied with advances in medicine, long living individuals will, slowly, become a reality. With this, new actors arrive in the social scene and the symbolic representation of old age will, eventually, gaining new meaning. The stereotype of the old as a decrepit, dying and without vitality seems to have larger adhesion in the social imaginary of aging. Lipovestky ${ }^{30}$ says that socialization between beings through tradition, religion and moral is giving ground to media information and the culture of spectacle.

The semantic that currently masks old age through euphemism and expressions about the passage of time constantly uses terms like "best age", "younger for e a longer time", - is the same that patholizes the aging process.

Brazilian culture (though not only) has in praising and overestimating youth, one of the country's main brands in representations abroad. It neglects, equally, knowledge and memory as a capital. A country with weak cultural roots doesn't value memory and tradition, reinforcing the voracious consumption of images as simulacrum.

While we don't re-think the way we look at death, aging won't be re-integrated as a natural stage of the life cycle, the old will remain marginalized and mentioning old age will continue to be taboo! In the same way we will continue to think of the old as a problem, a second class citizen, abandoned in nursing home as Foucault once identified to be the expulsion treatment of the mad, pushed away from the social scene. And in this condition, they are pushed to what Vilhena ${ }^{31}$ has called them: inhabitants of the suburbs of citizenship! The process of re-thinking old age is still active and is a result of an interdisciplinary dialogue among different areas of knowledge and, at times, distinct. The social relations and public policies will, as Debret (1999) points out, re-privatize old age, redirect the gaze that the old is obsolete as to

\footnotetext{
${ }^{6}$ Four out of ten elderly people started spending more with products they like, SPC Brazil research shows https://www.spcbrasil.org.br/pesquisas/ pesquisa/897 - acessado em 10/04/2016.
}

give voice, protagonism and space to this age segment.

To empower the elderly is to help them leave the place of isolation and invisibility. It's to atribute power where up to this point there was shame. Empowering the old is the equivalent of teaching them resistance points, presenting words as an outfit. Making them powerful is, at last - the same as accepting its edges knowing more consciously that the inclusion of new images will make the media space more diverse, fair and plural.

In the classroom, physical activity, playing cards at the town square, family relations, sexual relations and all spaces of sociability and associative life contexts, empowering the old is opening space for one more actor in the social scene. To resist is possible, and where there's resistance there is a symbolic game. And it's exactly this creative potency wherein lies all remaining desire... Where there's an immense contingencial desire, looking for satisfaction, there is life-as long, however, that we do not colonize this desire as to not immobilize its satisfaction in pre-determined ways. ${ }^{32-35}$

\section{Acknowledgements}

None.

\section{Conflict of interest}

The authors declare no conflict of interest.

\section{References}

1. Pocinho, Ricardo. Solitude and social abandonment in the elderly. In: Pocinho et al. Aging today - concepts and practices. Curitiba: Appris; 2013.

2. Bauman, Zygmunt, Leocini, et al. Born Liquid. Cambridge. Polity Press; 2018.

3. Elias, Norbert. The solitude of the dying, followed by, Aging and dying / Norbert Elias; Pliny Dentzien translation. Rio de Janeiro: Jorge Zahar editor; 2001.

4. Freud, Sigmund. Current considerations about war and death. IN: Introduction to narcissism: metapsychological essays and other texts. Complete Works volume XII. São Paulo: Companhia das Letras; 1915/2010.

5. Debert, Guita Grin, Oliveira, et al. Arenas of conflicts in the professionalization of the work of caring elderly people in Brazil. Sociology of work. 2016;86:44-63.

6. Vilhena, Junia, Novaes, et al. The shadow of a body that is announced: body, image and aging. Latin American Journal of Fundamental Psychopathology. 2014;1 (2):251-264.

7. Sibilia, Paula. One is what Google says one is: Editable life, between control and spectacle. Journal of Psychoanalysis. 2017;5(76):237-252.

8. Baudrillard, Jean. The consumer society. 70th ed. Portugal 2010.

9. Fernandes, Maria H. The bodily forms of suffering: the image of the hypochondria Latin American Journal of Fundamental Psychopathology, University Association of Research in Fundamental Psychopathology. São Paulo, Brazil. 2001;4(4):61-80.

10. Novaes, Joana V. Corps non civilisés.Un essai sur les femmes et les monstres. In: Masson C, Désrat PC, editors. Monstres Contemporains. Médecine, société et psychanalyse. 1st ed. Paris: Editions in Ppress. 2015;1:179-201.

11. From Priore, Mary. Personal communication. Instituto Geográfico Brasileiro; 2008.

12. http://www.psicologia.com.pt/artigos/textos/A0237.pdf

13. Novaes, Joana V. Body gun, body tool, body capital? Listening to MMA 
fighters. In: Body for what do I want? Uses, abuses and misuses. 1st ed. Rio de Janeiro/ Curitiba: Appris. 2012;1:125-155.

14. Novaes, Joana V. Enraged with affection, ashamed of hunger: body, maternity and childhood obesity. In: What body is this that walks with me always: Body, image and psyche suffering. 1st ed. Curitiba: Appris. 2016;1:111-1126.

15. Sibilia, Paula. The bodies visible in the contemporary: From media purification to artistic clarity. Kaypunku: Journal of Interdisciplinary Studies of Art and Culture. 2018;4:175-1198.

16. Bobbio, Noberto. The time of memory: Of senectute and other autobiographical writings. Norberto Bobbio: translation Daniela VersianiRio de Janeiro: Campus; 1997.

17. Ortega, Francisco, Vidal, et al. Culture: by the brain and in the brain? History, Sciences, Health-Manguinhos (Online). 2016;5(23):965-983.

18. Py L, Leibing A. The new old aging and gerontology in Brazil. AGHE Exchange, Washington. 2015;3(28):1-10.

19. Novaes, Joana V, Junia de. The tyranny of aesthetics: On women and their bodies. Rumus Scientific Journal of the University of Mindella. 2016;3:297-324.

20. Sant'anna, Denise Bernuzzi de. Beauty made in Brazil. Sigila (Paris). 2015;35:123-133.

21. Sant'anna, Denise Bernuzzi de. The imperative of beauty in Brazil. Confins (Paris). 2016;26:1-12.

22. Sant'anna, Denise Bernuzzi de. Old age: between destiny and history. The Third Age. 2017;27:8-19.

23. Debert, Guita Grin. Les migrations et le marché de soins aux personnes âgées. Vibrant (Florianópolis). 2016;13:89-101.

24. Vilhena Junia. In addition to the lived years: a reading of the clinicaldiscursive categories about old age. In: Pocinho et al. editors. Aging today - concepts and practices. Curitiba: Appris; 2013.

25. Jodelet, Denise. Folies et Represéntations Sociales. Paris. editor. PUF. 2004 Debert, Guita Grin. Aging, Gender and Sexuality in Brazilian Society. Anthropology \& Aging. 2014;34:238-250.
26. Debt, Guita G. Aging, Gender and Sexuality in Brazilian Society. Anthropology \& Aging. 2014;34:238-250.

27. Rosa, Carlos MV, Junia of aging and its possible destinations. A reflection on the work of the negative. Psychoanalytic Time. 2015;47:112-133.

28. Rosa, Carlos M, Vilhena, Junia of The silencing of old age. Social erasure and subjectivation process. Subjectivities. 2017;16: 9-19.

29. Debord, Guy. The society of the spectacle. Guy Debord. Translation Estela dos Santos Abreu. Rio de Janeiro: Counterpoint; 1997.

30. Lipovetsky, Gilles. From lightness: towards a civilization without weight. Translation Maria Lucia Machado. São Paulo: Companhia das Letras; 2017.

31. Is everything dominated? City, segregation and subjectivity. In: Vilhena J, editor. The Clinic at the University: theory and practice. Rio de Janeiro: Ed. PUC-Rio; São Paulo: Loyola; 2004.

32. Novaes, Joana R, Carlos MV, Junia de. Other times of living... Rethinking the aging. In: Ricardo Pocinho; Sónia Mairos Ferreira; Vítor Nuno Anjos. (Org.). Conversations of Psychology and Active Aging. 1st ed. Coimbra: Portuguese Association Conversas de Psicologia. 2017;1:98-125.

33. The malaise in civilization. Sigmund Freud; translation of Paulo César de Souza. 1st ed. São Paulo: Companhia das Letras; 2011 [1929/1930].

34. WHO. Active aging: a health policy / World Healtch Organization. Suzana Gontijo translation. Brasília: Pan American Health Organization; 2005.

35. Times of aging: body, memory and transience. In: Novaes, Joana V, editors. What body is this that always walks with me ?: body, image and psychic suffering. Curitiba, Appris. 2016:147-163. 